\title{
Correspondence
}

Rate pressure product

R.M. Jones, MB, FFARCS, Paul R. Knight, $P h D$ and Anne B. Hill, MB, FFARCS

Treatment of anaphylactic reactions

D.G. Larard, MB, FFARCS

Dantrolene and suxamethonium

S. Agoston, $M D$

Clive B. Collier, MB, FFARCS, FFARACS, $M R C P$

Jehovah's Witnesses and haemorrhage

J. Cundy, FFARCS

Anaesthesia and fractured neck of femur

L.J. Dunkin, MB, FFARCS

Local analgesia for circumcision in children

James M.B. Burn, MB, FFARCS

Monitoring and cockpit drill

K.N. Grigg, MB, FFARCS

Oxygen therapy by prescription only?

John A.R. Pook, FFARCS

Transcutaneous nerve stimulation in post-thoracotomy

C.M.H. Miller-Jones, BSC, MB, FFARCS,
1010

1011

1012

1013

1014

1015

1015

1017

1018
D. Phillips, $M B$, E.A. Pitchford, $M B$,

FFARCS and C.J. Smallpeice, MB, FFARCS

Colloid osmotic pressure

1018

Roger H. Jones, $M A, B M, M R C P$

Microlaryngeal surgery with the carbon dioxide

laser: is the Carden tube really necessary?

G. Vourc' $h, M D, M . L$. Tannieres, $M D$ and

C. Freche, $M D$

Recurring delayed adverse responses to general anaesthesia

David Beamish, FFARCS and David T. Brown, FFARCS

'Rhizolysis'

Nikolai Bogduk, $M B, B S c$

The Shy-Dräger syndrome

E.W. Simpson, $M B$

A pupil gauge

D.A. Pascoe, $S R N$

A new anaesthetic sensation?

Roger Durston, $M B$ and Christopher Aps, MB, FFARCS

\section{Rate pressure product}

We were pleased to see mention of rate pressure product (RPP) in Dr Roger Fletcher's article, Coronary disease and anaesthesia (Anaesthesia 1980; 35:27-34). We would like to emphasise the importance of this measurement and to make a number of personal observations concerning the anaesthetic management of patients with coronary artery disease. We have found this index of myocardial oxygen consumption $\left(\mathrm{MVO}_{2}\right)$ a valuable aid in managing patients, both for coronary artery surgery and in those with known ischaemic heart disease presenting for other forms of surgery.

The RPP is obtained by multiplying the heart rate by the systolic blood pressure. It has been shown that in any particular patient with ischaemic heart disease, the onset of angina appears at a constant RPP. 'At a RPP of 20000 most patients with angina will complain of some pain. ${ }^{2}$ Kaplan has correlated the RPP with clinical findings of myocardial oxygen supply and demand, imbalances. He has shown that ischaemia, as evidenced by electrocardiographic changes, occurred regularly when the RPP was greater than 12000 during the pre-bypass period in patients undergoing coronary artery surgery. ${ }^{3}$ In a more recent report $38^{\circ}{ }_{0}$ of patients undergoing non-cardiac surgery with documented, coronary-artery disease developed electrocardiographic (ECG) changes suggestive of myocardial ischaemia. All

All correspondence should be addressed to Dr T.B. Boulton, Editor of Anaesthesia, Royal Berkshire Hospital, Reading, RG1 5AN, England. The Correspondence section is sub-edited by Dr Richard H. Ellis, St Bartholomew's Hospital, London.

Letters must be typewritten on one side of the paper only and double spaced with wide margins. Copy should be prepared in the usual style and format of the Correspondence section. Authors must follow the advice as regards to references and other matters contained in 'Notice to Contributors' to Anaesthesia printed at the back of each issue. Degrees and diplomas of each author must be given in a covering letter.

Correspondence presented in any other style or format may be the subject of considerable delay and may be returned to the author for revision. 
but one of these patients developed ischemia when the RPP was above $11000 .{ }^{4}$ RPP is especially valuable as it does not require expensive equipment or invasive monitoring techniques and is therefore applicable for use in all surgical centres.

As in many conditions, the greatest potential dangers to the patient, especially those with ischaemic heart disease, exist during induction of anaesthesia and in the recovery period. Careful monitoring at these times, including the calculation of RPP and the prompt institution of the necessary measures to decrease pressure and/or heart, rate may lessen the risks of peri-operative myocardial ischaemia and its potential sequelae of frank infarction.

Beta-blockade is quite useful in decreasing heart rate and a variety of vasoactive drugs can be used to reduce blood pressure, acting on preload and afterload to a variable extent. It is our experience that agents with a greater emphasis on preload reduction have a more beneficial effect in treating peri-operative myocardial ischaemia. This might be anticipated as these will tend to reduce left ventricular end diastolic volume as well as vascular resistance, thus reducing both major components of left ventricular wall tension, a major determinant of $\mathrm{MVO}_{2}$ and endocardial blood flow. Additionally there is evidence that coronary artery perfusion is improved in the face of a stable afterload. ${ }^{5}$ Thus we prefer to use pentolinium rather than hydrallazine to decrease blood pressure for its greater emphasis on preload reduction. Additionally we have found pentolinium blocks sympathetic discharge and prevents activation of the renin-angiotension II system, preventing reflex increases in heart rate and myocardial contractility, thereby favourably influencing MVO. For a similar reason nitroglycerin (NTG) by primarily reducing venous tone and thus decreasing preload, may be more efficacious in treating elevated blood pressures in patients with ischaemic heart disease than sodium nitroprusside (SNP), which decreases arteriolar tone and thus primarily afterload. NTG, used for many years to afford relief of angina, has recently been employed as an intravenous infusion for intra-operative use. However, no stable, commercial preparation is yet available. Recently the use of intranasal NTG has been described. ${ }^{7}$ This is especially convenient since sterile techniques need not be employed. The solution may be made up by dissolving 20 tablets $(0.4 \mathrm{mg})$ in $10 \mathrm{ml}$ of saline; $0.5-2 \mathrm{ml}$ of this solution administered intra- nasaly using a syringe and at tached catheter (a 16 gauge intravenous catheter) when evidence of potential ischaemia occurs. NTG very quickly traverses mucous membranes and has a beneficial effect on myocardial oxygen supply, demonstrated on the electrocardiogram by ST and $\mathrm{T}$ wave changes, within a minute or two. These coincide with peak NTG blood levels. ${ }^{\text {? }}$

In conclusion we find careful clinical control of RPP using $\beta$-blockade and vasodilating agents which decrease preload primarily, to be a valuable adjunct in the effective management of patients with ischaemic heart disease. With careful control of heart rate and blood pressure, perioperative mortality and morbidy associated with myocardial infarction may be lessened in these patients.

Department of Anaesthesiology,

University of Michigan Hospital. Ann Arbor,

R.M. JONES

Michigan 48109

$U S A$

\section{References}

1. Cokninos DV, Voridis EM. Constancy of ratepressure-product in pacing induced angina pectoris. British Heart Journal 1975; 38:39-42.

2. RoBinson BF. Relation of heart rate and systolic blood pressure to the onset of pain and angina pectoris. Circulation 1967; 25:1073 83.

3. KaPlaN JA. Hemodynamic monitoring. In: Kaplan JA. ed. Cardiac Anesthesia. Clinical Cardiology Monographs. New York: Grune \& Stratton, 1979: $71-115$.

4. Roy WL, Edelist E, Gilbert B. Myocardial ischaemia during non-cardiac surgical procedures in patients with coronary-artery disease. Anesthesiology $1979 ; 51: 393-7$.

5. Clayman R, Johansen KH, Delaria GA, BernSTEIN EF. The hypertensive balloon. A beneficial synergism for the salvage of ischemic myocardium. Journal of Thoracic and Cardiovascular Surgery 1974; 68:80-9.

6. Knight PR, Lane GA, Nicholls MG, Tait AR, Nahrwold ML, Hensinger RN, Cohen PJ. Hormone and hemodynamic changes induced by pentolinium and propranolol during corrective scoliosis surgery. Anesthesiology; Accepted for publication

7. Hill AB, Bowley CJ, Nahrwold ML, KNight PR, TAIT AR, TAYlor MD, KIRSH MM, DENLINGER JK. Intranasal administration of nitroglycerin. Ancsthesiology 1979; 51:S67.

\section{Treatment of anaphylatic reactions}

I would like to support Dr Chow (Anaesthesia 1980; 35:77) in his plea for the early and specific use of adrenaline in the management of severe sensitivity reactions by comparing two personal experiences.

I recently anaesthetised a fit lady aged 33 years for a radical mastoidectomy. She was terrified prior to induction in spite of $20 \mathrm{mg}$ of oral diazepam. A test dose of Althesin was followed by a sleep dose and an intravenous infusion was started. Alcuronium $20 \mathrm{mg}$ was given which appeared to initiate a violent spasm of 